\title{
Effect of a Hard Sublayer on Contact Interaction and Wear Behavior of Electrodeposited Gold-Based Coatings
}

\author{
Alexander O. Lyazgin ${ }^{1, \text { a) }}$, Artur R. Shugurov ${ }^{1, b)}$, Alexey V. Panin ${ }^{1, c)}$, \\ and Evgeniy V. Shesterikov ${ }^{2,3, \text { d) }}$ \\ ${ }^{1}$ Institute of Strength Physics and Materials Science SB RAS, Tomsk, 634055, Russia \\ ${ }^{2}$ Research and Production Company "Micran”, Tomsk, 634034, Russia \\ ${ }^{3}$ National Research Tomsk Polytechnic University, Tomsk, 634050, Russia \\ ${ }^{a}$ Corresponding author: lyazgin@list.ru \\ b)shugurov@ispms.tsc.ru \\ c) pav@ispms.tsc.ru \\ d) evgen@micran.ru
}

\begin{abstract}
The mechanical properties and wear of electroplated $\mathrm{Au}-\mathrm{Ni}$ coatings deposited on beryllium bronze substrates with $\mathrm{Ni}$ or $\mathrm{Ni}-\mathrm{B}$ intermediate layers were investigated. It was revealed that the sublayer material has no significant effect on the hardness and the elastic modulus of the coatings. At the same time, the harder sublayer favors localization of plastic deformation and, thus, strain hardening of coatings in the course of tribological tests. The Ni-B sublayer was shown to provide significant wear reduction of $\mathrm{Au}-\mathrm{Ni}$ coatings as compared with the Ni sublayer.
\end{abstract}

Keywords: contact interaction, wear, multipass scratching, mechanical properties, electrodeposition, $\mathrm{Au}-\mathrm{Ni}$ coatings

\section{INTRODUCTION}

Electrolytic gold-based coatings are commonly used in electronic industry in manufacturing electrical contacts, connectors, etc. $[1,2]$. Such coatings must have high chemical and corrosion resistance, electrical conductivity, as well as low and stable contact resistance. To improve the wear resistance of Au coatings they are usually alloyed with small additions $(<1 \mathrm{wt} . \%)$ of $\mathrm{Ni}$ or Co [3]. Introduction of alloying elements increases the coating hardness due to their segregation at the grain boundaries without significant impact on the electrical conductivity of the coatings.

Typically, an intermediate layer is deposited between the coating and the substrate that prevents interdiffusion of materials and provides their high adhesion strength. At the same time, the physical and mechanical properties of the sublayer material have a significant influence on friction and wear of the coatings, especially in the case of their small thickness. The aim of this work is to reveal the effect of the sublayer material (Ni and Ni-B) on the mechanical characteristics and wear of electrodeposited $\mathrm{Au}-\mathrm{Ni}$ coatings.

\section{EXPERIMENTAL}

$\mathrm{Au}-\mathrm{Ni}$ coatings with the thickness of $1.5 \mu \mathrm{m}$ were electrodeposited on beryllium bronze substrates with preliminary electroplated $5 \mu \mathrm{m}$ thick $\mathrm{Ni}$ or Ni-B layers. The coatings and the sublayers were deposited at current densities of 2 and $15 \mathrm{~mA} / \mathrm{cm}^{2}$, respectively.

Mechanical and tribological properties of the coatings were studied using a universal NanoTest Platform 2 nanotester. The hardness and the elastic modulus were measured by nanoindentation with a Berkovich pyramid in the load range from 1 to $50 \mathrm{mN}$. Tribological tests were performed by multipass nanoscratching using a conical nanoindentor that moved along the sample surface at the speed of $10 \mu \mathrm{m} / \mathrm{s}$. 
TABLE 1. Surface roughness $R_{\mathrm{a}}$, hardness $H$, Young's modulus $E$ and elastic recovery of coatings after scratch tests under the maximum load of $50\left(Q_{50}\right)$ и $200 \mathrm{mN}\left(Q_{200}\right)$

\begin{tabular}{cccccccc}
\hline Sample & $\boldsymbol{R}_{\mathbf{a}}, \mathbf{n m}$ & $\boldsymbol{H}, \mathbf{G P a}$ & $\boldsymbol{E}, \mathbf{G P a}$ & $\boldsymbol{Q}_{\mathbf{5 0}}, \boldsymbol{\%}$ & $\boldsymbol{Q}_{\mathbf{2 0 0}}, \boldsymbol{\%}$ & $\boldsymbol{H} / \boldsymbol{E}$ & $\boldsymbol{H}^{\mathbf{3}} / \boldsymbol{E}^{\mathbf{2}}, \mathbf{M P a}$ \\
\hline $\mathrm{Ni}$ & 89 & $3.4 \pm 0.3$ & $197 \pm 8$ & 78 & 47 & 0.017 & 1.01 \\
\hline $\mathrm{Ni}-\mathrm{B}$ & 63 & $6.7 \pm 0.3$ & $183 \pm 5$ & 82 & 65 & 0.037 & 8.98 \\
\hline $\mathrm{Au}-\mathrm{Ni} / \mathrm{Ni}$ & 51 & $2.1 \pm 0.3$ & $102 \pm 5$ & 56 & 42 & 0.021 & 0.89 \\
\hline $\mathrm{Au}-\mathrm{Ni} / \mathrm{Ni}-\mathrm{B}$ & 71 & $2.1 \pm 0.2$ & $100 \pm 6$ & 51 & 40 & 0.021 & 0.93 \\
\hline
\end{tabular}

Wear of coatings was investigated with a UMT-1 friction machine in the "pin-on-disk" geometry on conditions of dry friction. The tests were performed under the load of $1.85 \mathrm{~N}$ and the sliding speed of $0.5 \mathrm{~m} / \mathrm{s}$. Balls made of hardened steel with the diameter of $3 \mathrm{~mm}$ were used as a rider. The wear of the Au-Ni coatings was determined by measuring the width of the wear tracks on the sample surface using an optical-television system. Surface topography of the wear tracks was investigated with a Quanta 200 3D scanning electron microscope (SEM), a Solver HV atomic force microscope (AFM) and a Zygo New View 6300 optical profilometer.

\section{RESULTS AND DISCUSSION}

Research of mechanical properties of $\mathrm{Ni}$ and $\mathrm{Ni}-\mathrm{B}$ layers by nanoindentation showed that the hardness of the $\mathrm{Ni}-\mathrm{B}$ layer is nearly two times higher than that of the Ni layer (see Table 1). The probable reason for the increase in $\mathrm{Ni}-\mathrm{B}$ hardness is boron segregation at the nickel grain boundaries during coating deposition [4]. On the contrary, the elastic modulus of the $\mathrm{Ni}-\mathrm{B}$ layer is slightly lower than that of $\mathrm{Ni}$. As a consequence, the $\mathrm{Ni}$ and $\mathrm{Ni}-\mathrm{B}$ layers are characterized by different values of the $H / E$ and $H^{3} / E^{2}$ ratios that determine the resistance of the material to the elastic and plastic deformation, respectively [5-7]. According to Table 1, the combination of high hardness and low elastic modulus allows reducing the contribution of plastic strain to the total strain that manifests itself in increasing the elastic recovery of the Ni-B layer as compared with Ni. This effect becomes more pronounced at higher applied load. As a result of the higher hardness and elastic recovery, the $\mathrm{Ni}-\mathrm{B}$ layer is characterized by considerably shallower residual scratches after multipass nanoscratching (Fig. 1).

Whatever the sublayer material is, the Au-Ni coatings are characterized by the similar values of hardness and Young's modulus as well as the residual scratch depth at the maximum load of $50 \mathrm{mN}$ (Fig. 1(a)). The difference in the residual scratch depth is observed only after the first pass and, seemingly, due to different initial surface roughness of the coatings. When increasing the maximum load up to $200 \mathrm{mN}$, the residual scratch depth on the surface of the coatings deposited on the Ni-B is lower than that in the case of the Ni sublayer. The difference in the scratch depth grows with increasing pass number. Table 1 shows that at a higher maximum load applied to the indenter the elastic recovery of the coating is reduced. This means the decrease in the contribution of elastic strain, and, as a consequence, an increase in that of plastic strain. Therefore, the coatings deposited on the Ni-B sublayer are assumed to be intensively strain hardened that provides for their plastic resistance under multipass scratching.

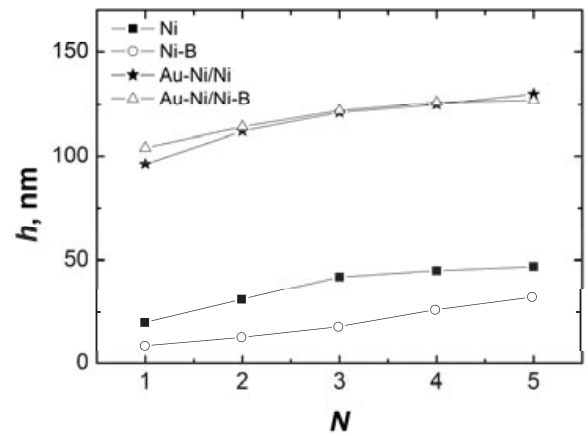

(a)

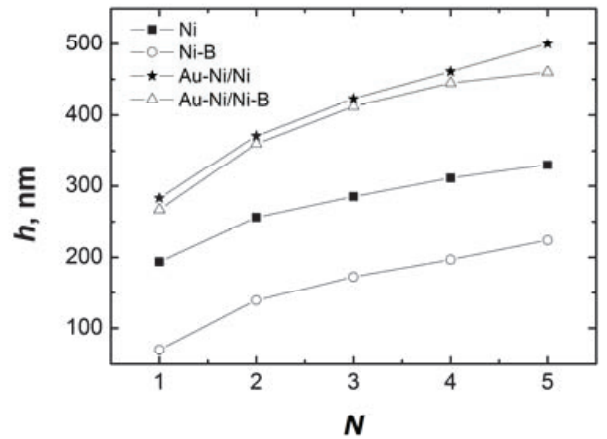

(b)

FIGURE 1. Residual scratch depth $h$ in the surface of the coatings as a function of the pass number $N$ at a maximum load of 50 (a) and $200 \mathrm{mN}$ (b) (adopted from [8]) 


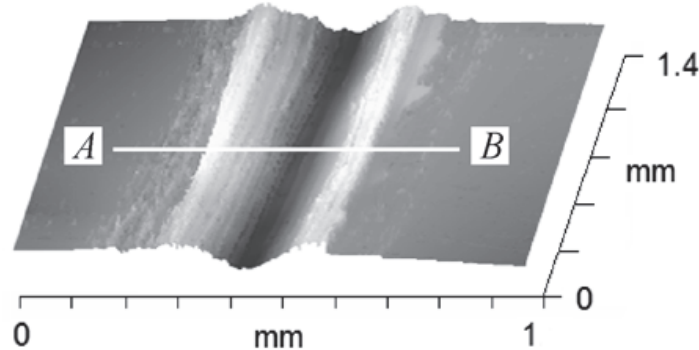

(a)

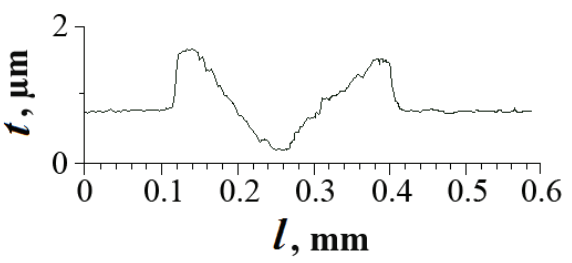

(b)

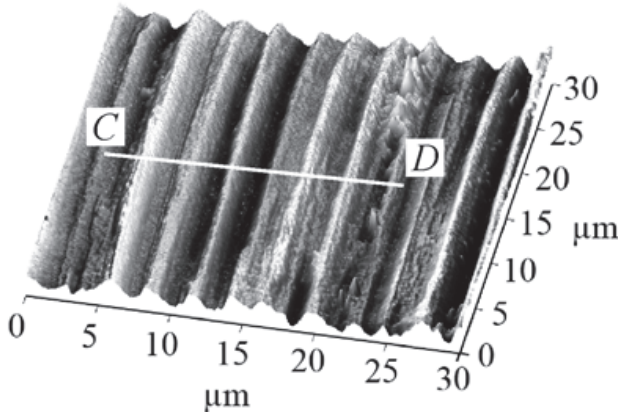

(c)

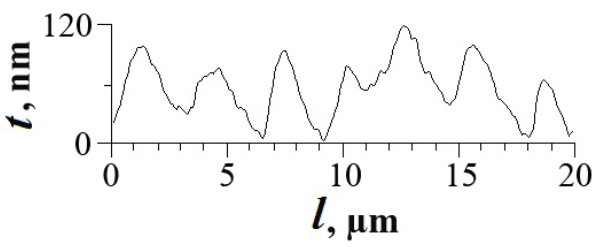

(d)

FIGURE 2. 3D optical (a) and AFM (d) images and corresponding profiles $A B$ (b) and $C D$ (d) of a wear track on the surface of $\mathrm{Au}-\mathrm{Ni}$ coating

Wear of the $\mathrm{Au}-\mathrm{Ni}$ coatings on conditions of dry friction is caused by their macroscopic elastoplastic deformation due to the action of the rider, interaction of microasperities on the friction pair surfaces as well as adhesive interaction [9-11]. Contact interaction between a hard rider and a rather soft coating under the only applied normal force is considered in terms of the classical Hertzian contact theory. The estimates show that without a hard interlayer between the $\mathrm{Au}-\mathrm{Ni}$ coating and the bronze substrate the maximum compressive stress in the center of the contact area would result in initiation of plastic deformation into the substrate, while the coating would be elastically deformed. A hard sublayer prevents from strain propagation into the substrate that induces the shift of the maximum stress into the coating. In this case, the maximum stress is estimated to be $945 \mathrm{MPa}$. Using the measured value of the coating hardness (see Table 1) the Tabor relation $\sigma_{\mathrm{y}} \approx H / 3$ [12] gives the value of $700 \mathrm{MPa}$ for the yield strength $\sigma_{\mathrm{y}}$ of the $\mathrm{Au}-\mathrm{Ni}$ coatings. Thus, the maximum stress exceeds the yield strength that means that plastic deformation of the coating deposited on a hard sublayer can be initiated before sliding the rider.

When applying the tangential force to the rider, combination of normal and tangential loads causes the area of maximum compressive stresses to displace towards the surface ahead of the rider [10]. Because the maximum stress was shown to exceed the coating yield strength, ploughing of the $\mathrm{Au}-\mathrm{Ni}$ coating occurs with formation of the pileup regions along the wear track (Fig. 2(a)), which height $(t)$ reaches $1.5 \mu \mathrm{m}$ (Fig. 2(b)). In turn, microasperities on the rider surface induce microscratches in the wear tack revealed with AFM (Fig. 2(c)). Analysis of the AFM-image profiles showed that the microscratch dimensions indicate that they seem to be formed due to plastic ploughing of the coating too (Fig. 2(d)). As in the case of the multipass scratching, the hard Ni-B layer leads to strain localization into the coating, and, as a consequence, to its more intensive strain hardening in comparison with the Ni sublayer. The nanoindentation shows that the wear track hardness of the Au-Ni coating deposited on the Ni-B sublayer increases by 20 percent after $5000 \mathrm{~s}$ wear tests.

Along with abrasive wear of the coatings by means of ploughing, their adhesive wear due to interaction with the rider also occurs. From the very beginning of the wear tests, a transfer layer is formed on the rider, because the tangential stress arising on rider sliding exceeds the cohesion strength of the coating that leads to tearing-off of its small flakes. Initially a thin gold transfer layer formed on the steel rider plays a role of a solid lubricant, which favors the decrease of the friction coefficient. 


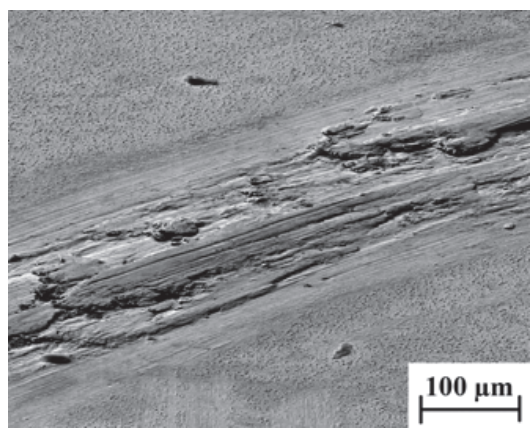

FIGURE 3. SEM-image of the transfer layer on a wear track of Au-Ni coating

Subsequently, intensive strain hardening of this prow reduces its plasticity so that its lubricating properties are considerably reduced. Because the prow and the wear track consist of the same material, it results in increasing the molecular contribution to the friction force and stronger adhesive interaction between the coating and the rider. The latter manifests itself as tearing-off of larger coating fragments and back transfer of the prow to the wear track. The following tests induce either secondary plastic ploughing of the transferred layer or its delamination and transfer along the wear track (Fig. 3). As shown above, more intensive strain hardening occurs in the coatings deposited on the harder Ni-B layer. This leads to the decrease of both abrasive and adhesive wear. As a result, the width of the wear tracks in the case of the Au-Ni coatings deposited on the Ni-B sublayer is 15 percent less than that of the coatings deposited on $\mathrm{Ni}$.

\section{SUMMARY}

Consideration of contact interaction of a hard rider with an Au-Ni coating deposited on a hard sublayer in terms of the Hertzian contact theory revealed that the sublayer results in the displacement of the area of maximum stresses from the substrate into the coating. Multipass scratching and wear tests on conditions of dry friction showed that the $\mathrm{Ni}$ and $\mathrm{Ni}-\mathrm{B}$ layers deposited between the $\mathrm{Au}-\mathrm{Ni}$ coating and the beryllium bronze substrate lead to strain localization in the galvanic coating. This is confirmed by intensive strain hardening of the coating in the wear track area that is most pronounced in the case of the $\mathrm{Ni}-\mathrm{B}$ sublayer, where the strain hardening of the $\mathrm{Au}-\mathrm{Ni}$ coating reaches 20 percent. As a consequence, the Ni-B sublayer provides for reduction of linear wear by 15 percent as compared with the Ni sublayer.

The work was performed in the framework of the Program of fundamental researches of State academies of sciences for 2013-2020.

\section{REFERENCES}

1. M. Braunovic, N. K. Myshkin, and V. V. Konchits, Electrical Contacts: Fundamentals, Applications and Technology (CRC press, Boca Raton, 2006).

2. Electrical Contacts: Principles and Applications, edited by P. G. Slade (CRC press, Boca Raton, 2013).

3. Y. Okinaka and M. Hoshino, Gold Bull. 31, 3 (1998).

4. C. Youyi, J. Ping, T. Li, and K. Jun, Trans. NFsoc. 1, 50 (1991).

5. A. Leyland and A. Matthews, Wear 246, 1 (2000).

6. J. Musil, F. Kunc, H. Zeman, and H. Poláková, Surf. Coat. Technol. 154, 304 (2002).

7. X. Z. Ding, X. T. Zeng, Y. C. Liu, Q. Yang, and L. R. Zhao, J. Vac. Sci. Technol. A, 22, 2351 (2004).

8. A. R. Shugurov, A. V. Panin, and E. V. Shesterikov, Tech. Phys. Lett., 37, 223 (2011).

9. E. V. Torskaya, Phys. Mesomech. 15(3-4), 245 (2012).

10. K. Holmberg, A. Laukkanen, H. Ronkainen, K. Wallin, S. Varjus, and J. Koskinen, Surf. Coat. Technol. 200, 3793 (2006).

11. H. Tian, N. Saka, and E. Rabinowicz, Wear, 142, 57 (1991).

12. D. Tabor, The Hardness of Metals (Clarendon Press, Oxford, 1951). 